\title{
SCIDOC
}

International Journal of Dentistry and Oral Science (IJDOS)

ISSN: $2377-8075$

\section{Pre-Eruptive Intracoronal Resorption: The Hidden Truth}

Research Article

Sruthi $S^{1}$, Deepa Gurunathan ${ }^{2 *}$

${ }^{1}$ Saveetha Dental College and Hospitals, Saveetha Institute of Medical and Technical Sciences, Saveetha University Chennai, India.

${ }^{2}$ Professor, Department of Pedodontics, Saveetha Dental College and Hospitals, Saveetha Institute of Medical and Technical Sciences, Saveetha University Chennai, India.

\section{Abstract}

\begin{abstract}
Aim: To evaluate the prevalence of pre-eruptive intra-coronal resorption (PEIR) in unerupted permanent teeth using a whole slew of panoramic radiographs of Chennai residents.

Design: Orthopantomograph (OPG) of 4700 patients from different parts of Chennai were retrospectively screened in the present study. Evaluation of patient details and OPG screening were done. Evaluation was based on the following dossier: age, sex, number of unerupted teeth, number of teeth showing PEIR defects, affected tooth type and number of PEIR in each radiograph.

Results: In total, 3568 OPG's had at least one unerupted tooth in 4700 patients, with a pervasiveness of $75.9 \%$. Of the 3568 patients screened, 2103 were male and 1465 were female. Intra-coronal resorption was observed in 20 of 3568 subjects. The age groups ranged between $4-15$ years.

Conclusion: PEIR defects were observed in 20 OPG's. Early diagnosis of PEIR and its enhanced awareness helps in proper treatment planning of the affected teeth.
\end{abstract}

Keywords: Radiograph; Prevalence; Intra-Coronal; Panoramic; Resorption.

\section{Introduction}

PEIR is an anomaly presenting as an abnormal, well circumscribed, radiolucent area, often occurring in the coronal dentin adjacent to the amelo-dentin junction of unerupted teeth [1-3] Most PEIR's are often detected as incidental findings in routine dental radiographs [4]. The depth of the lesion is adaptable and not often involves the pulp. Although some lesions progress rapidly, the others progress slowly before the tooth erupts into the oral cavity [5-8]. In most scenarios, a single tooth is affected, although cases involving several teeth have also been reported [9]. Most commonly affected teeth are molars and premolars [4].

PEIR can have three etiological factors (1) Chronic apical inflammation of primary teeth affecting the erupting successor, dental caries [10, 11, 12]; (2) Developmental mineralization defect of dentine $[13,12]$; (3) Resorption superimposed on existing developmental defects [10-14] The conventional theory describes the lesion as an idiopathic external resorption of coronal dentin; resorptive cells originating from the surrounding connective tissue or bone penetrating the developing tooth through a breach in the reduced enamel epithelium and cause dentin resorption $[13,15$, 16]. Factors to contemplate in timing the intervention include lesion size, expected time of tooth emergence, nature of the lesion (Static or Progressive), patient's caries risk [4, 17]. The prevalence of PEIR is of $3-6 \%$ of the patients and in $0.5-2 \%$ of the teeth $[16,18,19]$.

Forensic odontology is an emerging science and has a greater scope of development. Many methods have been developed to determine age, sex and ethnicity of the person using dental tissues. Every individual has a unique dentition which can sometimes be attributed to the dental procedures. Dentition of a person serves the purpose of individual identification and comparison. Forensic identification of dentition is dependent on the availability and accuracy of antemortem dental records. By comparing antemortem

*Corresponding Author:

Deepa Gurunathan,

Professor, Department of Pedodontics, Saveetha Dental College and Hospitals, Saveetha Institute of Medical and Technical Sciences, Saveetha University Chennai, India. Tel: 9994619386

E-mail: deepag@saveetha.com

Received: January 12, 2021

Accepted: January 22, 2021

Published: January 29, 2021

Citation: Deepa Gurunathan, Sruthi S. Pre-Eruptive Intracoronal Resorption: The Hidden Truth. Int J Dentistry Oral Sci. 2021;8(1):1455-1459. doi: http://dx.doi.org/10.19070/2377$8075-21000290$

Copyright: Deepa Gurunathan ${ }^{\circ} 2021$. This is an open-access article distributed under the terms of the Creative Commons Attribution License, which permits unrestricted use, distribution and reproduction in any medium, provided the original author and source are credited. 
and postmortem radiographs, forensic remains can be reliably identified. This raises the need for appropriate cataloging of dental records which is duly the duty of the dentist there by providing an information source in medico-legal, administrative, and for forensic purposes. Dental analysis plays an important role similar to fingerprint and DNA analysis.

To the best of our observation, there have not been any epidemiological studies of PEIR in Chennai residents. Consequently, the purpose of the current study was to observe for the presence of PEIR in unerupted teeth by examining OPG's of 4-15year old Chennai patients. In addition, these radiographs might help in forensic identification of PEIR in the future.

\section{Materials and Methods}

\section{Ethical Approval:}

The protocol for the current study was approved by the Institutional Review Board (SRB/MDS/PEDO/18-19/0007) from October 2018 - December 2018.

\section{Sample Selection:}

In this retrospective study, standard OPG's were taken as they are commonly taken in clinical practice for patients with developing dentition, and show the maximum number of teeth in a single radiograph. The sample for the current study consisted of 4700 OPG's [2754 (59\%) boys; 1946 (41\%) girls] from different parts of chennai with an age range of $4-15$ years.

\section{Inclusion Criteria}

Presence of at least one unerupted tooth with full crown formation, age less than 15 years. Supernumerary teeth and unerupted third molars and were included. Patients with documented medical and dental anomalies such as amelogenesis imperfecta, dentinogenesis imperfecta, and hypophosphatemic rickets were eliminated from the study. Radiographs which were not of optimal diagnostic quality were also excluded. Due to lack of definition of teeth in the anterior region of OPG, incisor teeth were excluded from examination. Also, radiolucencies on mandibular molars showed a linear appearance resembling buccal grooves were not recorded as PEIR defects.

\section{Radiographic Examination:}

OPG's used in this study were taken from different parts of Chennai. They were taken as standard OPG's. The examiner was trained to detect PEIR defects using OPG's which were not part of the study, and were assessed twice for calibration and reproducibility purposes. The intra-examiner correlation coefficient was measured using Kappa statistics which found to be 0.9.

A tooth beneath the bone and/or mucosa was considered as an unerupted tooth and those deviated from the normal eruption pathway were considered as ectopically positioned. According to the classification scheme of a study [19], the size of each defect relative to coronal dentine thickness was noted, whether it is (1) within one-third of the dentin thickness (2) or two-third of the dentin thickness (3) or extended through the full dentin thickness of the crown.

\section{Results}

A total of 4700 OPG's were evaluated in the current study. In total, 3568 OPG's had at least one unerupted tooth with a pervasiveness of $75.9 \%$. Of the 3568 OPG's screened, 2103 were male and 1465 were female. Intra-coronal resorption was identified in 20 teeth with a frequency of $0.5 \%$ (Table-1) The localization of intracoronal radiolucencies is shown in Table-1. Intra-cornal resorption was identified in both maxillary and mandibular teeth. 9 affected teeth were observed in maxilla $(0.2 \%)$, where as 11 were in the mandible $(0.3 \%)$. PEIR were seen to be equally distributed on both sides. Intra-coronal radiolucency by tooth type, location and size of the defect is documented according to male and female cases in Table-2. Of the 20 intra-coronal resorption, 9 (45\%) were seen in canine, followed by 7 molar teeth (35\%) and 4 premolar teeth $(20 \%)$. For the sizes of the defects scored relative to the width of dentin thickness, most prevalent $(50 \%)$ was a score of 2 and scores of 1 and 3 were equally prevalent (25\% each). (Table-2) (Fig-1,2,3).

\section{Discussion}

To the best of our observation, the present study was the first to screen for PEIR in Chennai residents. The tooth pervasiveness of PEIR in the present study $(0.5 \%)$ was similar to that of other studies using OPG's (Table-3) [3, 16, 19, 20, 21, 22, 23]. This low pervasiveness could suggest that all OPG's should be screened routinely for PEIR. The unerupted permanent incisors were not included in the current study as they were not well defined in the OPG's which were similar to those in Australian [3] and Jordian studies [22].

There were no obvious racial and gender differences in the prevalence of PEIR defects. A study (Seow et al 1999a) [3] reported that the PEIR was observed higher in mandibular first molar

Table 1. Demographic analysis, prevalence and localization of intra-coronal resorption.

\begin{tabular}{|c|c|c|c|c|c|}
\hline $\begin{array}{c}\text { Patients examined } \\
\text { Gender }\end{array}$ & $\begin{array}{c}\text { Patients with at least } \\
\text { one unerupted teeth }\end{array}$ & \multicolumn{4}{|c|}{ Intra-coronal resorption } \\
\cline { 2 - 6 } & Present(\%) & Absent(\%) & Present(\%) & Maxilla(\%) & Mandible \\
\hline Male & 2103 & 651 & 13 & 6 & 6 \\
\hline Female & 1465 & 481 & 7 & 3 & 5 \\
\hline Total & $3568(75 \%)$ & $1132(24 \%)$ & $20(0.5 \%)$ & $9(0.2 \%)$ & $11(0.3 \%)$ \\
\hline
\end{tabular}


Table 2. Distribution of patients with PEIR and radiographic features.

\begin{tabular}{|c|c|c|c|c|c|}
\hline Patient & Sex & Age(years) & Affected tooth & Location of PEIR & Size of PEIR \\
\hline 1 & Male & 10 & 13 & Distal & 2 \\
\hline 2 & Male & 13 & 28 & Distal & 2 \\
\hline 3 & Female & 14.5 & 18 & Mesial & 1 \\
\hline 4 & Male & 7 & 25 & Central & 2 \\
\hline 5 & Male & 15 & 28 & Mesial & 1 \\
\hline 6 & Male & 8 & 45 & Distal & 1 \\
\hline 7 & Female & 7 & 13 & Distal & 2 \\
\hline 8 & Female & 6.5 & 34 & Central & 2 \\
\hline 9 & Male & 9 & 43 & Central & 2 \\
\hline 10 & Female & 10 & 37 & Distal & 1 \\
\hline 11 & Male & 11 & 33 & Central & 3 \\
\hline 12 & Male & 13.5 & 38 & Mesial & 1 \\
\hline 13 & Female & 7 & 33 & Central & 3 \\
\hline 14 & Female & 8 & 33 & Central & 3 \\
\hline 15 & Male & 6 & 44 & Mesial & 2 \\
\hline 16 & Female & 14 & 18 & Central & 2 \\
\hline 17 & Male & 9 & 13 & Distal & 3 \\
\hline 18 & Male & 10 & 13 & Mesial & 2 \\
\hline 19 & Male & 15 & 48 & Central & 2 \\
\hline 20 & Male & 7 & 33 & Mesial & 3 \\
\hline
\end{tabular}

Score-1: Within one-third of the dentin thickness.

Score-2: Two-third of the dentin thickness.

Score-3: Extended through the full dentin thickness of the crown. (PEIR, Pre-eruptive intracoronalresorption).

Table 3. Prevalence studies of Pre-eruptive intracoronal radiolucencies.

\begin{tabular}{|c|c|c|c|c|c|c|}
\hline \multirow[b]{2}{*}{ Author, year } & \multicolumn{3}{|c|}{ Study design } & \multicolumn{2}{|c|}{ Population } & \multirow{2}{*}{$\begin{array}{c}\text { Tooth prevalence } \\
(\%, n / N)\end{array}$} \\
\hline & $\begin{array}{l}\text { Type of } \\
\text { study }\end{array}$ & $\begin{array}{l}\text { Radio } \\
\text { graphy }\end{array}$ & $\begin{array}{c}\text { Teeth } \\
\text { excluded }\end{array}$ & Country & Age (years) & \\
\hline Seow et al., 1999a [3] & Prospective & Bitewing & $\begin{array}{l}\text { Incisors \& } \\
\text { third molars }\end{array}$ & Australia & $6-10$ & $2 \%(163 / 9919)$ \\
\hline Ozden\&Acikgoz, 2009 [16] & Retrospective & OPG & None & Turkey & $14-73$ & $0.95 \%(28 / 2922)$ \\
\hline Seow et al., 1999b [19] & Prospective & OPG & Incisors & Australia & $3.5-25$ & $0.5 \%(57 / 11767)$ \\
\hline Wang et al., 2013 [20] & Retrospective & OPG & $\mathrm{N} / \mathrm{A}$ & China & $3.6-12.5$ & $0.7 \%(6 / 8171)$ \\
\hline Uzun et al., 2014 [21] & Retrospective & OPG & None & Turkey & $18-69$ & NA \\
\hline Al-Batayneh et al., 2014 [24] & Retrospective & OPG & Incisors & Jordan & $6-15$ & $0.62 \%(128 / 20788)$ \\
\hline Umansky et al., 2016 [25] & Retrospective & OPG & None & Israel & $4-53$ & NA \\
\hline Present study & Retrospective & OPG & Incisors & India & $4-15$ & $0.5 \%(20 / 4700)$ \\
\hline
\end{tabular}

(4\%), mandibular first premolar $(2 \%)$ and mandibular second molar $(1 \%)$ compared to maxillary premolars and molars [3]. Another study (Ozden\&Acikgoz 2009) disclosed that the most frquently damaged teeth were the mandibular second molar, followed by maxillary second premolar, maxillary central and maxillary canine [16]. However, in contrast to other studies, the presence of PEIR was found to be more in mandibular canine followed by maxillary canine, maxillary third molar, mandibular third molar, maxillary and mandibular premolars. In the present study, most PEIR were found in the central aspect of the crown (66.6\%) similar to the results seen in previous studies [16, 19, 21, 22, 23]. However, various studies evaluated that PEIR were also commonly found in the distal [20] and mesial $[3,24,25]$ aspects of the crown.

In the current study, all lesions were detected beneath amelo-dentin junction and extended to depths within dentine, as evaluated in previous studies (Hata et al. 2007, Grundy GE et al.1984, Seow et al. 1999b, Mc Donald \& Avery 2000) $[8,13,19,26]$ Seow et al $1999 \mathrm{~b}$, [19] descried that $40 \%$ of the defects continued to more than two-thirds of the thickness of the coronal dentine [19]. In the present study, most prevalent $(50 \%)$ was the score of 2 and the scores of $1 \& 3$ were the same (25\% each).

Present study involved radiographs specifically from the Dravidi- 
Figure 1. Score 1 PEIR defect located in the distal aspect of unerupted right mandibular second premolar crown.

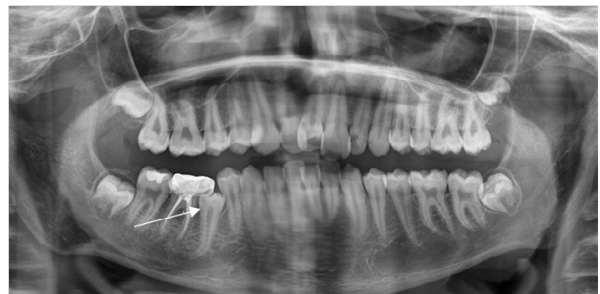

Figure 2. Score 2 PEIR defect located in the central aspect of the unerupted left mandibular first premolar crown.

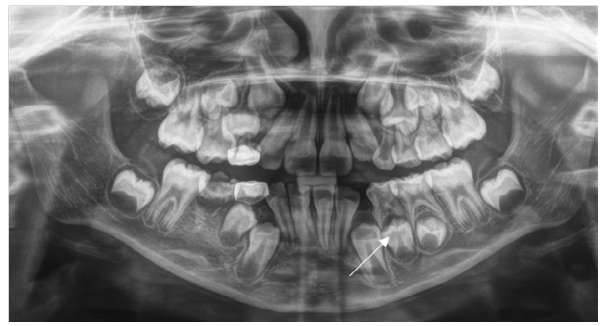

Figure 3. Score 3 PEIR defect located in the central aspect of unerupted left mandibular first premolar crown.

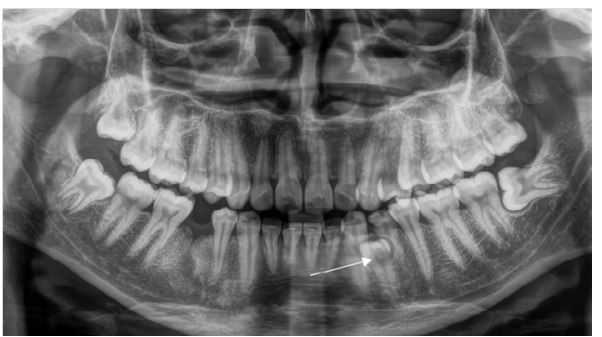

an population. Considering the large number of samples involved, the results of the study can be extrapolated to the Dravidian community. Further, longitudinal studies have to be conducted keeping the forensic aspect in mind as the presence of PEIR will help in assessing, handling and evaluation of previous records of the individual.

\section{Conclusion}

The pervasiveness of PEIR in the present study was $0.5 \%$. Teeth with highest prevalence of PEIR were the mandibular canines. The lesion was found primarily in mandibular teeth, as a single lesion, in the central part of the crown and had at least two-third of dentin thickness. Although, PEIR has a relatively low pervasiveness in the present study, it must be ensured that clinicians are aware of this lesion. A careful analysis during radiographic examination of unerupted teeth is highly required for early diagnosis and treatment of the lesion.

\section{References}

[1]. Brooks JK. Detection of intracoronalresorption in an unerupted developing premolar: report of case. J Am Dent Assoc. 1988 Jun;116(7):857-9.Pubmed PMID: 3164739.

[2]. Rutar JE. Paediatric dentistry: coronal radiolucency. Case reports. Aust Dent J. 1997 Aug;42(4):199-201.Pubmed PMID: 9316307

[3]. Seow WK, Wan A, McAllan LH. The prevalence of pre-eruptive dentin radiolucencies in the permanent dentition. Pediatr Dent. 1999 JanFeb;21(1):26-33.Pubmed PMID: 10029964

[4]. Counihan KP, O'Connell AC. Case report: pre-eruptive intra-coronal radiolucencies revisited. Eur Arch Paediatr Dent. 2012 Aug;13(4):221-6.Pubmed PMID: 22883363.
[5]. Holan G, Eidelman E, Mass E. Pre-eruptive coronal resorption of permanent teeth: report of three cases and their treatments. Pediatr Dent. 1994 Sep-Oct;16(5):373-7.Pubmed PMID: 7831146.

[6]. Seow WK. Multiple pre-eruptive intracoronal radiolucent lesions in the permanent dentition: case report. Pediatr Dent. 1998 May-Jun;20(3):195-8. Pubmed PMID: 9635317.

[7]. Klambani M, Lussi A, Ruf S. Radiolucent lesion of an unerupted mandibular molar. Am J OrthodDentofacOrthop. 2005 Jan 1;127(1):67-71.

[8]. Hata $\mathrm{H}$, Abe M, Mayanagi $\mathrm{H}$. Multiple lesions of intracoronalresorption of permanent teeth in the developing dentition: a case report. Pediatr Dent. 2007 Sep-Oct;29(5):420-5.Pubmed PMID: 18027778.

[9]. Spierer WA, Fuks AB. Pre-eruptive intra-coronal resorption: controversies and treatment options. J ClinPediatr Dent. 2014 Summer;38(4):326-8.Pubmed PMID: 25571683.

[10]. Muhler JC. The effect of apical inflammation of the primary teeth on dental caries in the permanent teeth. J Dent Child. 1957;24:209-10.

[11]. Rankow H, Croll TP, Miller AS. Preeruptive idiopathic coronal resorption of permanent teeth in children. J Endod. 1986 Jan;12(1):36-9.Pubmed PMID: 3456421.

[12]. Ignelzi MA Jr, Fields HW, White RP, Bergenholtz G, Booth FA. Intracoronalradiolucencies within unerupted teeth. Case report and review of literature. Oral Surg Oral Med Oral Pathol. 1990 Aug;70(2):214-20.Pubmed PMID: 2290652.

[13]. Grundy GE, Pyle RJ, Adkins KF. Intra-coronal resorption of unerupted molars. Aust Dent J. 1984 Jun;29(3):175-9.Pubmed PMID: 6594989.

[14]. Savage NW, Gentner M, Symons AL. Preeruptiveintracoronalradiolucencies: review and report of case. ASDC J Dent Child. 1998 Jan-Feb;65(1):36-40. Pubmed PMID: 9559084.

[15]. Singer S, Abbott PV, Booth DR. Idiopathic coronal radiolucencies in unerupted permanent teeth. Case reports. Aust Dent J.36:32-7,2009.

[16]. Özden B, Acikgoz A. Prevalence and characteristics of intracoronalresorption in unerupted teeth in the permanent dentition: a retrospective study. Oral Radiol. 2009 Jun;25(1):6-13.

[17]. Czarnecki G, Morrow M, Peters M, Hu J. Pre-eruptive intracoronalresorption of a permanent first molar. J Dent Child (Chic).2015;81:151-155.

[18]. Seow WK. Pre-eruptive intracoronalresorption as an entity of occult caries. Pediatr Dent. 2000 Sep-Oct;22(5):370-375.Pubmed PMID: 11048303. 
[19]. Seow WK, Lu PC, McAllan LH. Prevalence of pre-eruptive intracoronal dentin defects from panoramic radiographs. Pediatr Dent. 1999 SepOct;21(6):332-9.Pubmed PMID: 10509334.

[20]. Wang Y, Chen J, Liu H. Prevalence of preeruptiveintracoronal radiolucency in Chinese children from panoramic radiographs. Chin J Dent Res. 2013 Jan 1;16(2):153-6.

[21]. Uzun I, Gunduz K, Canitezer G, Avsever H, Orhan K. A retrospective analysis of prevalence and characteristics of pre-eruptive intracoronalresorption in unerupted teeth of the permanent dentition: a multicentre study. IntEndod J. 2015 Nov;48(11):1069-76.Pubmed PMID: 25354246.

[22]. Demirtas O, Dane A, Yildirim E. A comparison of the use of cone-beam computed tomography and panoramic radiography in the assessment of preeruptive intracoronalresorption. ActaOdontol Scand. 2016 Nov;74(8):636641.Pubmed PMID: 27669814.
[23]. Demirtas O, TarimErtas E, Dane A, Kalabalik F, Sozen E. Evaluation of pre-eruptive intracoronalresorption on cone-beam computed tomography: A retrospective study. Scanning. 2016 Sep;38(5):442-447.Pubmed PMID: 26752617.

[24]. Al-Batayneh OB, AlJamal GA, AlTawashi EK. Pre-eruptive intracoronal dentine radiolucencies in the permanent dentition of Jordanian children. Eur Arch Paediatr Dent. 2014 Aug 1;15(4): 225-236.

[25]. Umansky M, Tickotsky N, Friedlander-Barenboim S, Faibis S, Moskovitz M. Age Related Prevalence of Pre-Eruptive Intracoronal Radiolucent Defects in the Permanent Dentition. J ClinPediatr Dent. 2016;40(2):103-6.Pubmed PMID: 26950809

[26]. McDonald RE, Avery DR (2000) Dentistry for the child and Adolescent. 7thedn. St. Louis: Mosby, pp. 105-50. 